\title{
Protestas, participación y educación pública: discursos sobre lo público en las movilizaciones estudiantiles en Chile $^{1}$
}

Protestos, participação e educação pública: discursos sobre o público nas mobilizações estudantis no Chile

\section{Protests, participation and public education: discourse about the public matter in students' mobilizations in Chile}

\author{
Héctor Berroeta ${ }^{2}$ \\ Juan Sandoval ${ }^{2}$
}

\begin{abstract}
RESUMEN
El presente artículo se propone analizar los significados que le asignan los estudiantes universitarios chilenos a las prácticas de protesta y ocupación del espacio público que se realizan en el marco de las movilizaciones estudiantiles del año 2011. Para esto se diseña una muestra intencional compuesta por estudiantes de universidades públicas y privadas de la región de Valparaíso y se utiliza como técnica de producción de información el focusgroup y como técnica de análisis un procedimiento de análisis de contenido. Los resultados se organizan en cinco ejes temáticos que expresan el modo como los jóvenes universitarios significan sus formas de acción colectiva: "contra el modelo desde el modelo", "protesta y espacio público", "la transformación de lo público: individualismo y mercantilización”, "ocupar los medios de
\end{abstract}

DOI: $10.1590 / 0104-4060.36578$

1 Este artículo se inscribe en el trabajo del primer autor en el Núcleo de Investigación "Cultura Política y Espacio Público" del Convenio de Desempeño para las Humanidades, Artes y Cs. Sociales de la Universidad de Valparaíso y el trabajo del segundo autor en el Proyecto FONDECYT N. ${ }^{\circ} 11130690$.

2 Universidad de Valparaíso. Valparaíso, Chile. Av. Brasil, 2140. 
comunicación y construir opinión pública", y "los estudiantes como concientizadores de la sociedad". Se concluye que los jóvenes universitarios establecen significados complejos acerca de sus prácticas de protesta y movilización social, que se expresan en formas de acción no convencional $\mathrm{y}$ en tensiones con el modelo del que son herederos.

Palabras claves: protestas estudiantiles; espacio público; Chile; educación pública.

\title{
RESUMO
}

O presente artigo tem como objetivo analisar os significados que estudantes universitários chilenos atribuem às práticas de protesto e ocupação do espaço público que têm sido realizadas no marco das mobilizações estudantis no ano 2011. Para isto foi planejada uma amostra intencional composta por estudantes de universidades públicas e privadas da região de Valparaíso, Chile, utilizando-se como técnica de produção de informação o focusgroup e como técnica de análise um procedimento de análise de conteúdo. Os resultados foram organizados em cinco temas que expressam a maneira como os estudantes universitários representam as formas de ação coletiva: "contra o modelo, tomando como referência o próprio modelo", "protesto e espaço público", "a transformação da esfera pública: o individualismo e a mercantilização", "ocupação dos meios de comunicação e construção da opinião pública" e "conscientização dos alunos e da sociedade". Concluiu-se que o jovem universitário estabeleceu significados complexos a respeito de suas práticas de protesto e de mobilização social, que se expressam em formas de ação não convencional e em tensões com o modelo do qual são também herdeiros.

Palavras-chave: protesto estudantil; espaço público; Chile; educação pública.

\begin{abstract}
The present article aims at analyzing the meanings assigned by the Chilean university students to the protests practices and occupation of public spaces, which have been carried out in the framework of the student protests of 2011. For that purpose, an intentional sample composed of students from public and private universities in the region of Valparaíso, Chile, was designed. As information production technique, we used the focus group. As analysis technique, the "content analysis" was used. The results were organized into thematic categories, which express the way in which university students signify forms of collective action: "against the model, considering the model itself", "protest and public space", "transformation of the public scope: individualism and commercialization", "occupying the communication
\end{abstract}


media and building public opinion" and "the students as consciousness-raising of society". We conclude that young university students established complex meanings about their practices of protest and social mobilization, expressed in forms of unconventional action and tensions with the model of which they are heirs.

Keywords: students' protests; public space; Chile; public education.

\section{Introducción}

La sociedad chilena constituye la primera experiencia de implementación sistemática del modelo de desarrollo neoliberal en América Latina (GÓMEZ, 2008). Su instauración comienza después del golpe de Estado de 1973 a partir de la gran influencia que asumen los llamados 'chicago boys' sobre el programa económico del gobierno militar. La implementación de estas políticas neoliberales dio lugar a una verdadera "revolución", no sólo económica, sino también sociocultural, que transformó a Chile de una manera muy profunda (MOULIÁN, 1997; GARRETÓN, 2000).

De este modo, con mayor profundidad que en otras sociedades de América Latina, la revolución neoliberal que experimentó Chile provocó que el mercado se ubique en el centro de la vida en sociedad (ARAUJO; MARTUCCELLI, 2012), pasando a regular no sólo las relaciones económicas, sino también aquellos servicios que fueron la base de los derechos de la ciudadanía social, desplazando al Estado a una labor meramente burocrática y de control social. Un ámbito en el cual se puede evidenciar con claridad este proceso de transformación es en el sistema de educación superior.

En efecto, según los datos entregados por el informe "La educación superior en Chile" (ORGANIZACIÓN PARA LA COOPERACIÓN Y EL DESARROLLO ECONÓMICOS, 2009), en el período 1990-2008 la matrícula del sistema de educación superior chileno aumentó en $176 \%$, alcanzando un total de 678 mil alumnos, equivalente a 5.8 veces la matrícula existente el año 1980. Según cifras oficiales (Sistema de Educación Superior - SIES, 2013), al año 2013 existen 1.184 .805 estudiantes en el sistema de educación superior, distribuidos en un $27,5 \%$ en universidades tradicionales adscritas al Consejo de Rectores, un $32,2 \%$ en universidades privadas y un 40,3\% en los Institutos Profesionales (IP) y Centros de Formación Técnica (CFT) ${ }^{3}$.

3 El sistema universitario chileno se compone de tres subsistemas: un sistema estatal con instituciones de propiedad del estado pero que no reciben su financiamiento total del Estado, un 
Este proceso de expansión se produjo a partir de la mercantilización del sistema de educación, proceso que transformó a las Universidades (incluyendo a las Universidades Estatales) en entidades que deben autofinanciarse a partir de los aranceles de sus estudiantes. Esta mercantilización del sistema ha supuesto una drástica disminución del aporte público a la educación superior, el cual es uno de los más bajos del mundo (0,5 del PIB - Producto Interior Bruto), transformándola en un bien privado que debe ser financiado por quienes lo adquieren, como ocurre con cualquier otro producto o servicio del mercado.

A partir de la década del 2000, una parte importante de los estudiantes que logran acceder a la educación superior a partir de este proceso de expansión mercantil empieza a vivir cada vez con más fuerzas las consecuencias negativas del modelo: endeudamiento, mala calidad de la oferta educacional, segregación socioeconómica, problemas de empleabilidad después de estudiar. Es precisamente la acumulación de malestar con respecto a estas consecuencias del modelo la que se expresa en el ciclo de protestas estudiantiles que se produce a partir del año 2011 (MAYOL, 2012).

Este ciclo de movilizaciones puso en entredicho los beneficios del modelo de desarrollo y se constituyó en la cara visible de esta nueva forma de malestar. Es interesante destacar que en Colombia, otro país donde las transformaciones neoliberales han sido profundas, también se produce el año 2011 un ciclo de movilizaciones estudiantiles en contra de los procesos de mercantilización de la educación (ARCHILA, 2012), mostrando ambos movimientos características discursivas equivalentes. Sin embargo, en la región también nos encontramos con movilizaciones estudiantiles diferentes, como el caso de Venezuela, donde estas protestas se han definido en una relación de antagonismo con un gobierno de orientación anti-neoliberal.

Con independencia de sus diferencias, lo que se puede desprender de los ciclos de protestas estudiantiles de los últimos años en la región, y especialmente del caso chileno, es que los jóvenes universitarios han recuperado protagonismo político a partir del desarrollo de formas de acción política no convencionales que irrumpen con fuerza en el espacio público. En este contexto, el presente trabajo se propone analizar los significados que le asignan los estudiantes universitarios chilenos a las prácticas de protesta y ocupación del espacio público llevadas a cabo en el marco de las movilizaciones estudiantiles por la defensa de la educación pública del año 2011.

sistema tradicional privado con corporaciones de derecho privado que reciben parte de su financiamiento del Estado y un sistema privado-privado con instituciones que no reciben financiamiento del Estado. No obstante, los estudiantes de los tres tipos de instituciones pueden acceder a los mismos instrumentos de financiamiento a través de becas y créditos que entrega el Estado. 


\section{Protestas estudiantiles como formas de acción política no convencionales}

El ciclo de movilizaciones estudiantiles que se vive en Chile desde el año 2011 se caracteriza por poner en práctica formas de acción política no convencionales. Su accionar, se desarrolla con autonomía de las formas tradicionales de acción vinculadas a los partidos políticos y más bien se caracteriza por ser acciones no convencionales centradas en la ocupación del espacio público.

Autores clásicos (KLANDERMANS, 1984; DALTON, 1988) han utilizado ampliamente como medio de clasificación de la acción política los términos convencional/no convencional. Siguiendo la caracterización propuesta por Rucht (1992), entendemos que la acción política convencional se refiere al conjunto de comportamientos que se circunscriben a la regulación normativa de la participación política, siendo la conducta más destacada el voto y la referencia institucional más importante el Estado y los partidos políticos. Por su parte, la acción política no convencional se refiere a comportamientos diversos que no se corresponden necesariamente con el orden normativo y que puede incluir desde una marcha hasta la desobediencia civil. Melucci (1996) emplea el término acción directa para referirse a estas formas de acción, y al respecto sostiene que serían formas de intervención colectiva que se sostienen en niveles mínimos de organización y que constituirían experiencias de participación alternativa y ejercicio de la democracia directa.

La acción política no convencional ha tendido a predominar en los llamados nuevos movimientos sociales como feministas, ecologistas, pacifistas (RUCHT, 1992) y en los movimientos estudiantiles. Por ejemplo, Aguilera (2010) plantea que la acción colectiva de los jóvenes es mayoritariamente no convencional, ya que se produciría sin mediaciones institucionales, transcurriría en espacios públicos y semi-públicos, muchas veces de manera descentralizada; y, que a pesar de su espontaneidad, demandarían grandes niveles de coordinación.

Podemos identificar dos ámbitos específicos a partir de los cuales se problematiza la acción política no convencional. La primera tiene que ver con la superposición histórica entre la tecnología de la información y las formas no convencionales de acción política de los jóvenes, especialmente desde el punto de vista de la convocatoria y coordinación del timing de las protestas en los espacios públicos (SÁBADA, 2012). La masificación de las nuevas tecnologías posibilitó la emergencia de formas de acción-performance como los flash-mobs o smartmobs, que con frecuencia no se apoyan en identidades colectivas previas sino en la efervescencia tecnológica y el deseo de transgresión. Por ejemplo, 
Valderrama (2013) estudió la apropiación masiva de las Tecnologías de Información y Comunicación (TIC) en las acciones de protesta estudiantiles en Chile, mostrando que estas tecnologías amplían la extensión y eficacia de las redes de los jóvenes.

La segunda es la tensión entre democracia representativa y democracia directa en las formas de acción política no convencional de los jóvenes, lo que ha supuesto el desarrollo de prácticas cada vez más autónomas de las estructuras partidistas a través de la promoción de colectivos como formas de organización y por medio de prácticas donde predomina la horizontalidad en sus formas de participación y la deliberación asambleística en su toma de decisiones (AGUILERA, 2010; BRO, 2011). Al respecto, Hatibovic, Sandoval y Cárdenas (2012) estudiaron los discursos de universitarios chilenos sobre la acción política, estableciendo que el ejercicio de la democracia directa es un objetivo valorado por los grupos políticamente activos.

La influencia de las formas no convencionales de acción política han llevado a que se proponga una nueva comprensión de los movimientos sociales a partir de la denominada "construcción social de la protesta" (MELUCCI, 1996), entendiendo estas acciones como definiciones colectivas en torno a una demanda común, frente a la pérdida de legitimidad del sistema y al incremento del sentido de la eficacia social, dando origen a un enfoque propiamente psicosocial del estudio de las protestas (KLANDERMANS, 1997).

La novedad de estas formas de acción política donde se mezcla la influencia de las nuevas tecnologías, las manifestaciones de las protestas acción-performance, la participación horizontal y las asambleas, es que constituyen formas de movilización que se proponen ocupar el espacio público, al constituirse en formas de acción colectiva que pretenden visibilidad pública, al mismo tiempo que buscan reivindicar el carácter público de los espacios donde se ejerce su propia acción.

\section{El espacio público como ámbito de acción colectiva}

El significado y alcance de las protestas estudiantiles que se desarrollan a partir del año 2011 se debe analizar en el marco de las transformaciones que ha venido viviendo el espacio público como ámbito de construcción de la ciudadanía y la vida en sociedad.

La categoría de espacio público tiene una larguísima tradición en la filosofía y las ciencias sociales, cuyos primeros antecedentes se pueden encontrar en el 
debate clásico acerca de la polis ateniense, mientras que sus desarrollos actuales los encontramos en los autores que problematizan las consecuencias del capitalismo neoliberal en la vida social contemporánea. Para efectos de este análisis, nos interesa abordar el problema de cómo se configura el espacio público en la sociedad contemporánea a partir de tres visiones: "el espacio público perdido"; "el espacio público como construcción de civilidad” y "el espacio público como espacio de control y disputa" (BERROETA; VIDAL, 2012).

El Espacio Público Perdido corresponde a los planteamientos que describen la pérdida del espacio público democrático en la sociedad contemporánea y que denuncian la emergencia de fenómenos de privatización, en lo que se ha llamado la disolución del espacio público. Se cuestiona la capacidad cohesionadora del sistema de espacios públicos y la creciente privatización urbana, cuyas manifestaciones ejemplares se encuentran en la substitución de las calles y las plazas por un conjunto de artefactos urbanos de dominio privado y la transformación del paisaje urbano por fenómenos de homogenización de la ciudad, la hipervigilancia y el control espacial.

El Espacio Público como Espacio de construcción de civilidad corresponde a la posición que sostiene que el espacio público es el ámbito principal de la cultura urbana y de la ciudadanía, cuya calidad, multiplicación y accesibilidad depende en buena medida el progreso de la ciudad. Esta perspectiva, que sin negar las consecuencias que la visión de la pérdida describe sobre espacio público, reivindica la necesidad de proyectar un mejor y más pertinente espacio público.

El Espacio Público como Espacio de control y disputa es una perspectiva crítica de la concepción romántica de un espacio público igualitario y accesible, posición desde la cual se analiza la disputa entre el control de lo urbano y la subversión de las prácticas de apropiación. Esta perspectiva plantea que el espacio público nunca ha sido un lugar armónico y completamente accesible, se señala que siempre ha sido un lugar donde se han dado dinámicas inestables y procesos de exclusión.

Desde esta visión el espacio público sólo se constituye como tal cuando es apropiado por los usuarios, un espacio sólo es público mediante un trabajo de cualificación que remite a los momentos de acción y a las estructuras prácticas de la experiencia (JOSEPH, 1999). Es decir, las características físicas sólo se constituirían en espacio público en el momento en que son apropiadas.

Esta perspectiva del espacio público parece ser la que se pone en juego en las formas de acción no convencional desarrolladas por los jóvenes chilenos en el ciclo de protestas que se inician el año 2011, al configurarse como un espacio en disputa entre los movimientos estudiantiles y el Estado, de modo que los estudiantes demandan reivindicar el carácter plural, abierto y ciudadano del espacio público, mientras que el Estado promueve el orden público y la seguridad de las 
personas en la ciudad. Como bien plantea Di Masso (2009), desde esta visión, el núcleo ontológico del espacio público es la dialéctica dominación-contestación, poder y resistencia, orden-transgresión, entre públicos y contrapúblicos en situación de desigualdad, en nuestro caso de estudio, entre estudiantes movilizados como poder constituyente y el Estado y sus instituciones como poder constituido.

\section{Metodología}

La presente investigación se realizó desde una perspectiva cualitativa. En ella participaron 64 jóvenes de entre 19 y 24 años de edad, estudiantes de diversas carreras de las universidades públicas y privadas de la región de Valparaíso y distribuidos en 28 mujeres y 36 hombres. La producción de datos fue realizada mediante grupos focales, realizando un total de 8 grupos de entre 6 y 9 participantes cada uno. Los criterios de conformación de cada grupo fueron la representación equilibrada de hombres y mujeres, la diversidad de carreras y universidades de origen y el año de ingreso a la educación superior. La producción de los grupos se realizó entre agosto y noviembre del año 2012 y fue realizada en dependencias de la Universidad de Valparaíso.

El contacto y convocatoria fue realizada por estudiantes de la carrera de Psicología de la Universidad de Valparaíso. Los participantes fueron invitados a "conversar acerca del movimiento estudiantil del año 2011". Quienes accedieron a participar, lo hicieron previa información de los objetivos del estudio y su procedimiento, y del resguardo de la confidencialidad y el anonimato.

$\mathrm{El}$ análisis de la información fue realizado por los investigadores responsables, en las etapas sucesivas de comparación continua (STRAUSS; CORBIN, 2002), propias del modelo de la teoría fundada, triangulando codificaciones y criterios de construcción y aplicación de categorías emergentes.

\section{Resultados}

Los resultados que a continuación se presentan corresponden a los cinco ejes identificados en el proceso de análisis axial de codificación de los relatos de los participantes del estudio. Cada uno de estos ejes constituye una dimensión de los significados que le asignan los estudiantes universitarios, a las prácticas 
de protesta y ocupación del espacio público llevadas a cabo en el marco del ciclo de movilizaciones estudiantiles iniciado el año 2011.

El primer eje, denominado "Contra el modelo desde el modelo", muestra las contradicciones ideológicas de los jóvenes al momento de argumentar sus demandas; el segundo eje, "Protesta y Espacio Público", despliega los diversos significados que circulan en torno a las acciones de ocupación del espacio público; el tercer eje, "La transformación de lo público: individualismo y mercantilización", describe la relación que se propone entre los cambios sociopolíticos de la sociedad chilena y la emergencia del movimiento estudiantil; el cuarto eje, "Ocupar los medios de comunicación y construir opinión pública", refiere a la compleja relación entre el movimiento estudiantil y los medios de comunicación; y finalmente, el quinto eje, "Los estudiantes como concientizadores de la sociedad", articula los relatos en torno al efecto transformador que el movimiento estudiantil ha tenido sobre la sociedad chilena.

\section{a) Contra el modelo desde el modelo}

Los jóvenes señalan que la reivindicación central del movimiento estudiantil es la gratuidad de la educación superior, la cual se produce en el marco de un profundo cuestionamiento al modelo de desarrollo. Sin embargo, en estos discursos sobre la gratuidad se identifica un relato paradójico, ya que los estudiantes no son capaces de salir del marco ideológico dominante y tienden a utilizar los principios individuales del mismo modelo para relativizar la pertinencia de esta demanda: por un lado, plantean que aquellos que tienen condiciones económicas deben pagar la educación, y por otro, valoran el pago económico como un factor de motivación individual.

Ahora bien también el tema de las peticiones, por ejemplo, claro debe ser algo razonable, porque igual estamos pidiendo, como decías tú, hace un rato, todo de una, por ejemplo la igualdad de la educación para todos, porque claro, si tenemos educación para todos van a estar aprovechándose los que no tienen la necesidad de ese beneficio (G3).

Que la educación sería lo ideal que fuera gratuita, lamentablemente no encuentro que sea exactamente lo necesario. Muchas personas que tienen recursos, yo encuentro que deberían pagarla, sino no lo encontraría muy justo, y lamentablemente encuentro que una mentalidad que está entre las personas, es que lo que es pagado se cuida más que lo que es regalado (G4). 
Otro contenido de este relato paradójico de los jóvenes es la reivindicación del mérito individual como condición necesaria para el acceso a beneficios sociales, visión que no rompe con el sistema de los subsidios individuales. Esta misma lógica es la que sustenta el argumento retórico que explica la desvinculación que se produce entre los jóvenes y el movimiento social al momento de egresar de la universidad.

[...] por algo terminamos la movilización y volvimos a clases. Nosotros decíamos: voy a perder la beca, voy a perder el año, o sea, el mismo control te lo vas poniendo tú mismo [...]. Claramente, los ideales cambian al salir de la universidad, porque claramente al tener más edad uno toma más responsabilidad: tienes que trabajar, ver tus hijos. El precio que debes pagar ahí es mucho mayor (G8).

Esta paradoja se expresa incluso en la analogía del intercambio comercial, asociada a los derechos de consumidor, que utilizan algunos jóvenes para justificar las conductas violentas en el marco de las protestas.

Como lo mismo que comentaba con amigos míos es el ejemplo que si uno va a un negocio, o por ejemplo va a aún servicio público privado y a uno no lo atienden, uno empieza a reclamar, y uno se empieza a alterar, se empieza a alterar, se empieza a alterar, y al final termina peleando y quizá hasta yéndose a las manos porque no lo atienden, no ser escuchado entonces es algo natural, ver la manera ultra pacífica es más utópico (G2).

\section{b) Protesta y espacio público}

Para los jóvenes, la acción política se vincula fundamentalmente con la ocupación de un espacio físico, siendo la acción en el espacio virtual un objetivo complementario. La apropiación de lo público a través de "acciones no convencionales" emerge como la estrategia definitoria de la acción colectiva, razón por la cual los jóvenes perciben como legítimas las acciones orientadas a "perturbar" el orden cotidiano del espacio público a través de acciones directas y espontáneas. Sin embargo, a pesar de esta legitimación de las prácticas no convencionales, se puede identificar una valoración negativa de aquellas acciones asociadas a la violencia y una positiva a las prácticas consideradas 
como "estéticas" o "creativas", definiendo como límite de la acción deseable la destrucción física de "lo público". Los jóvenes realizan una distinción retórica que excluye de la categoría "estudiante" a quienes realizan actos de violencia, siendo el estudiante aquel que está informado y que despliega acciones no convencionales asociadas al significante "pacifista" y que busca proyectar una imagen positiva del movimiento social.

Yo por lo menos no me imagino como un movimiento social sin ocupar el espacio público. Para mí no basta solamente con facebook o por las redes sociales. Tiene que haber un movimiento social en los espacios públicos, o sea, no me imagino sin marchar, sin rayar, sin cortar calles. Para mí ya no sería movimiento social (G8).

Yo creo que la apropiación del espacio público tiene que ver con una idea de democratización, o sea, hay una idea de democratizar ciertos espacios públicos, de apropiarlos, de hacerlos públicos, que la gente participe, de que no tengan miedo de salir (G4).

Yo siento que hay distintas maneras de ocupar los espacios en los movimientos estudiantiles, como fueron las llamadas marchas pacíficas, que eran más artísticas con bailes y que se yo, la "besatón"4 y esas cosas que se hicieron que eran muy simpáticas para la prensa (G2).

Si bien la protesta en el espacio público es legitimada como la acción central de un movimiento social, se establece un juicio crítico sobre la efectividad de estas acciones para lograr sus objetivos. La protesta emerge como un artefacto efímero cuyo sentido es el cambio de visión en un público espectador. Los relatos de los jóvenes expresan una desvalorización de la eficiencia de las acciones no convencionales pacifistas dentro de la protesta, cuestionando su capacidad para expresar el descontento social y para generar una reacción en los interlocutores políticos. Sin embargo, las mismas acciones de violencia también son entendidas como prácticas no convencionales, al definirse como actos espontáneos que no responden a la planificación clásica de los movimientos sociales. La violencia es considerada un momento performático más de la protesta, que muchas veces sería legitimado como estrategia para generar cambios, apareciendo como la 
expresión de un descontento estructural que va más allá de la reivindicación del movimiento estudiantil.

Es bakán expresarse con cantos, bailes, pero en realidad no hay nada que celebrar. Que las marchas sean un carnaval no va, porque debieran expresar un descontento social. Una forma de manifestarlo es con violencia. No estoy de acuerdo, pero es válida [...]. A pesar que son muchas las personas que se están manifestando, salen a las calles a marchar, las autoridades hacen oídos sordos, o sea, es como hablar con la pared (G8).

[...] los chicos de la población, digamos que venían y participaban en las manifestaciones sociales, yo muchas veces conversé con ellos y no veía efectivamente en ellos un rollo así con la educación gratuita, ni nada, o sea, ellos llevaban un descontento, muchas veces sin mayor trasfondo, pero es porque ellos generalmente viven violentados, entonces, ellos de alguna manera van y demuestran esa violencia, digamos con más violencia (G3).

\section{c) La transformación de lo público: individualismo y mercantilización}

El relato de los jóvenes establece una relación entre los cambios experimentados por el modelo económico y el problema de la educación en Chile. Al respecto, describen cómo estas transformaciones determinan el acceso a la educación, ya no sólo desde la posibilidad de pago, sino a partir de las condiciones de base que determinan el acceso, definiendo sujetos aptos y no aptos para acceder a ella.

Al final eso se ve como un servicio más de consumo del modelo neoliberal, no sé, aquí a nivel de América, Uruguay o Argentina por ejemplo, tenemos educación gratuita, igual Brasil. Entonces la idiosincrasia se ha creado con este pensamiento de que la educación es un derecho y no es un servicio de consumo, en cambio a aquí se ve como tú dices, las becas, los créditos, claro la persona que tiene más plata [...]. Como que clasificamos demasiado a las personas por el lado desde el que viene, y si viene de un liceo tiene una oportunidad muy baja de que entre a la universidad (G3). 
Dadas las condiciones actuales de privatización e individualización de la sociedad chilena, los jóvenes presentan un relato con muy poca esperanza de que se pueda producir un cambio.

[...] yo creo que tiene que ver con que la gente acá le cuesta involucrarse de lleno en lo que son los cambios del país, les cuesta porque yo he visto los dos comentarios, como tú dices, verlo desde el lado creativo y lindo, pero también por el otro lado, pero eso es más que nada porque yo creo que la gente acá tiene miedo a hacer cambios radicales, ese es el problema (G2).

Los relatos de los jóvenes también muestran el modo como ha penetrado el modelo neoliberal en las prácticas sociales, dando cuenta de una suerte de naturalización de las condiciones de opresión, que incluyen a la educación.

Pero el tema debiera ser hacia otro análisis, o sea, lo público y lo privado manifiestan cómo se está privatizando el mundo de lo público. Ya no nos pertenece nada. El transporte para qué decirlo: un chiste. ¿Una burla no es cierto? Cuento corto: me subo así apretado, lleno de gente. El objetivo es, por lo general, la plata, o los hijos, el bienestar de mi familia, de mi casa, mi auto, mi trabajo, mi... El espacio público se agotó en el egoísmo y el egoísmo es el sistema político, social, cultural, etcétera, etcétera. No sé cuándo, no sé cómo, caímos en esa maquinaria y poderla soportar (G8).

A partir de estos procesos de cambio, los jóvenes entienden que se produce la pérdida del Espacio Público. Para ellos habría un antes, anterior a la dictadura militar, donde sí habría existido un espacio público democrático, configurando una visión romántica de un pasado en el cual habría existido el intercambio, la confianza y la constitución de un espacio común, de manera muy distinta al que se constituiría a partir de los fenómenos de individualización que vive la sociedad actual.

En otros tiempos, antes del '73, existía un tipo de vida social diferente: el tema de los espacios de los barrios. Con lo que pasó después del golpe, el tema de los toques de queda y tener miedo a decir ciertas cosas porque te van a denunciar. Y los espacios públicos estaban como dados, 
estaban presentes, no había que ganarlos. No se cuestionaba "hay que hacer cosas ahí". Ahora no hay confianza para conversar en la calle, el saludo al vecino. También se han ido perdiendo, te han ido aislando. Tu carrera es sólo tuya, tu crédito es sólo tuyo (G5).

\section{d) Ocupar los medios de comunicación y construir opinión pública}

Para los jóvenes, el fin último de la protesta es lograr presencia en los medios de comunicación. Entienden que las protestas estudiantiles establecen una disputa por el espacio público mediático como los medios, sobre la base de una desconfianza básica con ellos, al ser asociados a grupos de poder con objetivos antagónicos al movimiento estudiantil. Los medios son percibidos como parciales, condición que explicaría que la violencia capture la pauta informativa sobre las manifestaciones estudiantiles.

Yo digo por lo mismo, el motivo de la protesta es causar bulla o sea romper con los esquemas cosa de ser escuchados. Al final el estudiante trata de generar el cambio de conciencia pero los medios de comunicación no te ayudan para eso, o sea estamos, al final estamos luchando contra los medios, que le mandan una sola mirada a la gente: que lo estudiantes son delincuentes, que los estudiantes cuando marchan hacen destrozos (G6).

Si bien los relatos valoran las distintas prácticas no convencionales que se producen en las protestas estudiantiles, la evaluación de los jóvenes es que muy pocas de estas acciones logran captar la atención de los medios y del público en general, y aun cuando algunas de ellas lo logran, la forma de expresión in-visibiliza el contenido del mensaje del movimiento.

El tema de los indignados en Barcelona, Madrid, estuvo harto tiempo. Dormir en carpas y aparecieron los sistemas de sonido y hubo música y buena onda pero también se les deshizo el movimiento y ahí están los españoles con cuánto \% de cesantía con la crisis económica hasta el cuello. Entonces, puedes pelear con los pacos, vamos a pelear con los pacos, o atentemos contra los sistemas de votación a través de un hackeo, o sea, todo tipo de lucha es válida, eso está claro de hace tiempo. Sin embargo, la pantalla mediática no ha permitido entender el mensaje (G2). 


\section{e) Los estudiantes como concientizadores de la sociedad}

Los jóvenes desarrollan un relato que reivindica la capacidad del movimiento estudiantil para provocar cambios sobre la sociedad en su conjunto, valorando el efecto que ha tenido este ciclo de protestas en la recuperación de lo público, poniendo en el debate la tensión entre los medios de comunicación y la acción de la ciudadanía. Se identifica una narrativa acerca del movimiento estudiantil como un actor concientizador, que posibilita pasar de la pasividad a la acción, al promover la participación como medio de transformación social.

[...] el tema de cómo se ha evidenciado la violencia también en la calle, tiene múltiples lecturas, sin embargo, yo creo que nos tendríamos que quedar con que a pesar de que hoy se puede ver lejana la pasividad, se volvió a ver el descontento, yo personalmente valoro el hecho de que la gente haya sido capaz de salir, lo veo como una instancia, manifiesta del hecho de atreverse, también simbólica respecto a qué es lo que significa y a posicionarnos nuevamente en el debate de lo público y lo privado (G4).

Este rol concientizador de los estudiantes, los jóvenes se lo explicarían por la distancia generacional que tendrían con la dictadura militar, auto-percibiéndose como una generación libre del miedo y capaz de salir al espacio público a demandar sus derechos. Se entienden a sí mismos como jóvenes motivados por la existencia de una sociedad injusta, basada en un modelo de desarrollo que genera una profunda desigualdad social.

Al ser generación post-dictadura, como no crecimos bajo represión, tenemos todas las ganas el derecho y el poder de querer usar los espacios públicos para poder protestar y decir que no está bien la cosa como está. Todos nos damos cuenta que no está bien repartido, pucha la gran cantidad de dinero que llega, está repartido en muy pocas familias de Chile y la gran mayoría vive con poca plata y eso no está bien. Porque todos en el fondo ocupamos el mismo espacio, y la gente ya está cansada de eso y no tienen miedo de protestar, antes sí (Pamela, G3).

La evaluación que tienen los jóvenes de los efectos del ciclo de protestas estudiantiles transita entre una visión crítica con respecto a los objetivos específicos del movimiento estudiantil, cuyos logros serían de menor alcance, y 
una visión favorable de las consecuencias que este movimiento ha tenido en la activación de la ciudadanía, en la recuperación del espacio público y en el aumento de la conciencia de la sociedad.

Como que el movimiento estudiantil se agotó, así como que no sé, si no fuimos capaces, o no sé pero no se dio el hecho de poder articularse como sociedad, quizás ahora con el hecho y las actividades de los otros colectivos más adelante, quizás seamos capaces de generar un movimiento mucho más amplio, que era la apuesta del movimiento estudiantil que por el momento nunca ha logrado (G1).

\section{Discusión}

A partir del análisis relacional de los ejes identificados en la fase anterior, es posible establecer cómo se organizan los significados que los jóvenes universitarios construyen sobre sus acciones de protesta y ocupación del espacio público. Estos significados se articulan en tres tópicos fundamentales: el lugar de las prácticas no convencionales en las protestas estudiantiles, los significados que le asignan los jóvenes al espacio público y la relación de las prácticas de protesta de los estudiantes con las transformaciones neoliberales de Chile.

El primer punto tiene que ver con la valoración que los universitarios realizan de las prácticas no convencionales de acción política (RUCHT, 1992). Tal como propone Aguilera (2010), los jóvenes participantes en este estudio entienden sus prácticas de protesta como acciones no mediatizadas institucionalmente, que transcurren en el espacio público y que demandan altos niveles de creatividad y coordinación. Si bien los jóvenes valoran positivamente estas formas de acción no convencional, cuestionan su efectividad. En efecto, los significados de estas prácticas están cruzados por el problema de la eficiencia y la visibilidad pública de la protesta, emergiendo en los jóvenes el dilema sobre cómo estas prácticas logran impactar en la opinión pública en general y en los medios de comunicación en particular. Podríamos decir que estamos frente a una significación de la acción colectiva como artefacto de producción comunicacional (FERRY, 1995).

En este contexto, surge la pregunta por el lugar que ocupa la violencia en las prácticas no convencionales de los jóvenes y el nivel de legitimidad que tendrían estas prácticas en las protestas estudiantiles. Al respecto, los jóvenes al referirse a la violencia realizan dos operaciones discursivas que vale la pena 
destacar, la primera es establecer una disyunción entre los propios estudiantes y el actor que encarna la violencia, como una manera de excluir las acciones violentas de su propia identidad como sujeto de las movilizaciones. La segunda es legitimar la "violencia como reacción o respuesta", lo anterior a partir de la diferenciación discursiva que realizan entre la violencia directa y explicita (protestas callejeras) y la violencia indirecta e implícita (sistema económico y político altamente desigual), de modo que podríamos decir que para los jóvenes esta última forma de violencia sería la base de la primera, constituyendo por lo tanto su causa y justificación (SILVA, 2013).

El segundo tópico tiene que ver con los significados que le asignan los jóvenes al espacio público en las protestas estudiantiles, significados ambivalentes, que transitan indistintamente por las concepciones del espacio público como un espacio perdido, como un escenario en disputa y como un ámbito cívico (BERROETA; VIDAL, 2012). En efecto, por un lado, los jóvenes reivindican la necesidad de una recuperación del espacio público perdido tras la dictadura militar y que sería representado con un evidente sentido de la idealización por los jóvenes, como un espacio democrático y comunitario. Al mismo tiempo, los jóvenes entienden el espacio público como un escenario de conflicto, en el cual se debe disputar el contenido informativo de la opinión pública con los medios de comunicación de masas y el uso y ocupación material de la ciudad con las fuerzas policiales. Finalmente, el relato de los jóvenes también recurre al discurso cívico que legitima el uso del espacio público a partir de su condición democrática, de modo que la protesta emerge como una acción de materialización de este carácter democrático del espacio público (JOSEPH, 1999).

El tercer tópico se relaciona con el modo como los estudiantes universitarios vinculan sus prácticas de protesta con las transformaciones del neoliberalismo en Chile. En este sentido, tal como propone Mayol (2012), los jóvenes que participaron en este estudio se auto-perciben en una relación de antagonismo con el modelo de desarrollo, definiendo que su objetivo es una suerte de "politización" del malestar existente con el modelo neoliberal. Desde esta perspectiva, la participación en las protestas emerge como una decisión individual, como expresión de una identidad personal definida por haber logrado un alto nivel de conciencia respecto de las contradicciones sociales del modelo. Sin embargo, es relevante destacar que la penetración del discurso neoliberal en Chile es tan profunda que incluso los relatos de estos jóvenes se ven colonizado por dimensiones propias de la mercantilización y la sociedad de consumo. Un ejemplo evidente de lo anterior es el discurso paradójico con el cual enfrentan algunos jóvenes el debate sobre la gratuidad de la educación. Lo anterior no es necesariamente sorprendente cuando se tiene en cuenta que una parte importante de los jóvenes que hoy estudian en las universidades chilenas lograron acceder 
a ellas precisamente a partir de la expansión mercantil que experimentó la matrícula del sistema de educación superior en los últimos 20 años.

Podemos concluir que los hallazgos de este trabajo nos indican que los jóvenes universitarios se autodefinen como actores conscientes, "indignados" frente a la profundización de la desigualdad, la segregación escolar y la privatización de los derechos sociales como la educación, proponiéndose ellos mismos como los actores políticos capaces de articular el malestar social que surge frente a las consecuencias negativas del modelo neoliberal. A partir de esta representación de sí mismos, los jóvenes universitarios establecen significados complejos acerca de sus prácticas de protesta y movilización social. Son significados en los cuales se expresan las características de las formas de acción no convencional y las prácticas no institucionales de ocupación del espacio público, pero también se manifiestan las tensiones de un grupo social que protesta frente a un modelo del cual ellos mismos son herederos.

Si bien es evidente que a partir del año 2011 los estudiantes chilenos pusieron un signo de interrogación sobre las bondades del modelo de desarrollo neoliberal y que sus acciones de protesta pusieron en cuestión los estereotipos acerca de los jóvenes como actores despolitizados, queda aún por ver la profundidad y alcance de la crítica que encarna el movimiento estudiantil chileno, ya que en tanto actores socializados en la hegemonía de una racionalidad neoliberal también están ellos mismos cruzados por las contradicciones que semejante racionalidad impone a los sujetos (SANDOVAL; HATIBOVIC, 2010).

Por lo tanto, podemos sugerir, a modo de comentario final, que el desafío que enfrentan los jóvenes universitarios chilenos en los próximos años es precisamente cómo lograr a partir de su discurso de la política como movimiento y participación no convencional, constituir un antagonismo político con la hegemonía cultural del neoliberalismo. Veremos si el movimiento estudiantil chileno es capaz de transformar el malestar en torno a los efectos no deseados del neoliberalismo en demandas políticas que posibiliten la construcción de un modelo de desarrollo diferente.

\section{REFERENCIAS}

AGUILERA, O. Acción colectiva juvenil: De movidas y finalidades de adscripción. Nomada, n. 32, p. 81-97, 2010.

ARAUJO, K.; MARTUCCELLI, D. Desafios comunes. Retrato de la sociedad chilena y sus individuos. Santiago de Chile: Ediciones LOM, 2012. 
ARCHILA, M. El movimiento estudiantil en Colombia, una mirada histórica. OSAL, Buenos Aires: CLACSO, v. XIII, n. 31, p. 71-103, 2012.

BERROETA, H.; VIDAL T. La noción de espacio público y la configuración de la ciudad: fundamentos para los relatos de pérdida, civilidad y disputa. Polis, v. 11, n. 31, p. 57-80, 2012.

BRO, N. Condiciones culturales en la constitución de identidades políticas en el Chile actual. Algunas reflexiones a partir del caso del movimiento estudiantil secundario de 2006. Polis, v. 10, n. 28, p. 51-68, 2011.

DALTON, R. Citizen Politics in western democracies. Public Opinion and Political Parties in the United State, Great Britain, West Germany and France. Nueva Jersey: Chatham House Publishers, Inc., 1988.

DI MASSO, A. Public space in conflict: place meaning as contested interaction and ideological action. Tesis (Doctorado) - Universitat de Barcelona, Barcelona, 2009.

FERRY, J. Las transformaciones de la publicidad. En: FERRY, J., WOLTON, D. (Ed.). El nuevo espacio público. Barcelona: Gedisa, 1995.

GARRETÓN, M. La sociedad que vivi(re)mos. Introducción sociológica al cambio de siglo. Santiago de Chile: Ediciones LOM, 2000.

GÓMEZ, J. Política y ciudadanía en una sociedad neoliberal avanzada, Chile 1990-2007. Cuadernos del CENDES, n. 67, p. 59-83, 2008.

HATIBOVIC, F.; SANDOVAL, J.; CÁRDENAS, M. "Posiciones de sujeto" y acción política universitaria: Análisis de discurso de estudiantes de Universidades de la región de Valparaíso. Última Década, v. 20, n. 37, p. 111-134, 2012.

JOSEPH, I. Retomar la ciudad: El espacio público como lugar de la acción. Medellín: Universidad Nacional de Colombia, 1999.

KLANDERMANS, B. Mobilization and participation: Social-psychological expansions of resource mobilization theory. American Sociological Review, v. 49, n. 5, p. 583-600, 1984.

. The Social Psychology of Protest. Oxford: Blackwell, 1997.

MAYOL, A. El derrumbe del modelo: La crisis de la economía de mercado en el Chile contemporáneo. Santiago: Lomediciones, 2012.

MELUCCI, A. Challenging Codes: Collective Action in the information Age. Cambridge: Cambridge University Press, 1996.

MOUliÁn, T. Chile Actual, Anatomía de un Mito. Santiago de Chile: Arcis-LOM, 1997. ORGANIZACIÓN PARA LA COOPERACIÓN Y EL DESARROLLO ECONÓMICOS. Revisión de políticas nacionales de educación: La educación superior en Chile. Santiago: OCDE y Banco Mundial, 2009. 
RUCHT, D. Estrategias y formas de acción. En: DALTON, R.; KUECHLER, M. (Comp.). Los nuevos movimientos sociales. Valencia: Ediciones Alfons el Magnanim, 1992.

SÁBADA, I. Acción colectiva y movimientos sociales en las redes digitales. Aspectos históricos y metodológicos. ARBOR Ciencia, Pensamiento y Cultura, v. 188, n. 756, p. 781-794, 2012.

SANDOVAL, J.; HATIBOVIC, F. Socialización política y juventud: el caso de las trayectorias ciudadanas de los estudiantes universitarios de la región de Valparaíso. Última década, v. 18, n. 32, p. 11-36, 2010.

STRAUSS, A.; CORBIN, J. Bases de la investigación cualitativa: Técnicas y procedimientos para desarrollar la teoría fundamentada. Medellín Colombia: Universidad de Antioquía, 2002.

SILVA, F. Violencia Política e identidad. Breve lectura acerca de la incidencia de la violencia en la construcción de la identidad en el Chile actual. En: BANDA, C.; NAVEA, V. (Comp.). En Marcha: Ensayos sobre arte, violencia y cuerpo en la manifestación social. Santiago: Adrede Editores, 2013.

VALDERRAMA, L. Jóvenes, ciudadanía y tecnologías de información y comunicación. El movimiento estudiantil chileno. Revista Latinoamericana de Ciencias Sociales, Niñez y Juventud, v. 11, n. 1, p. 123-135, 2013.

Texto recebido em 20 de maio de 2014. Texto aprovado em $1^{\circ}$ de julho de 2014 . 